\section{Commentary: AVNeo (Ozaki) and transaortic mitral valve repair using autologous pericardium only for aortomitral endocarditis: The perfect solution in double-valve invasive aortomitral endocarditis?}

\author{
Oliver J. Liakopoulos, MD
}

Surgical reconstruction of infective aortic and mitral valve endocarditis (IE) involving the aortomitral curtain (ie, intervalvular fibrosa) is technically demanding with suboptimal early and mid-term outcomes. ${ }^{1,2}$ In one of the largest retrospective series, Navia and coworkers ${ }^{3}$ from the Cleveland Clinic recently published long-term clinical outcomes of 138 patients with double-valve IE requiring reconstruction of the intervalvular fibrosa. Transaortic double-valve replacement (Commando procedure) was performed in approximately $60 \%$ of cases, whereas $40 \%$ received an aortic valve replacement (AVR) with mitral valve repair (hemi-Commando). The intervalvular fibrosa was routinely reconstructed using an allograft, pericardial, or Dacron patch, ${ }^{2,3}$ and aortic valve/root replacement was performed with an allograft $(64 \%)$, biological prosthesis $(30 \%)$, or mechanical prosthesis $(5 \%)$. Operative mortality was $20 \%$ in the overall cohort, with a $13 \%$ mortality for the hemi-Commando cohort. Overall late survival at 1, 5, and 10 years was $67 \%, 48 \%$, and $37 \%$, respectively. At an 8 year follow-up, freedom from recurrent IE and redo surgery was $55 \%$ and $50 \%$, respectively. Importantly, clinical

\footnotetext{
From the Department of Cardiac Surgery, Kerckhoff-Clinic Bad Nauheim, Campus Kerckhoff, University of Giessen, Giessen, Germany.

Disclosures: The author reported no conflicts of interest.

The Journal policy requires editors and reviewers to disclose conflicts of interest and to decline handling or reviewing manuscripts for which they may have a conflict of interest. The editors and reviewers of this article have no conflicts of interest.

Received for publication May 26, 2020; revisions received May 26, 2020; accepted for publication June 2, 2020; available ahead of print June 15, 2020.

Address for reprints: Oliver J. Liakopoulos, MD, Department of Cardiac Surgery, Kerckhoff-Clinic Bad Nauheim, Campus Kerckhoff, University of Gießen Benekestr 2-8, 61231 Bad Nauheim, Germany (E-mail: o.liakopoulos@ kerckhoff-klinik.de).

JTCVS Techniques 2020;3:108-9

2666-2507

Copyright $(2020$ The Authors. Published by Elsevier Inc. on behalf of The American Association for Thoracic Surgery. This is an open access article under the CC BY-NCND license (http://creativecommons.org/licenses/by-nc-nd/4.0/).

https://doi.org/10.1016/j.xjtc.2020.06.007
}

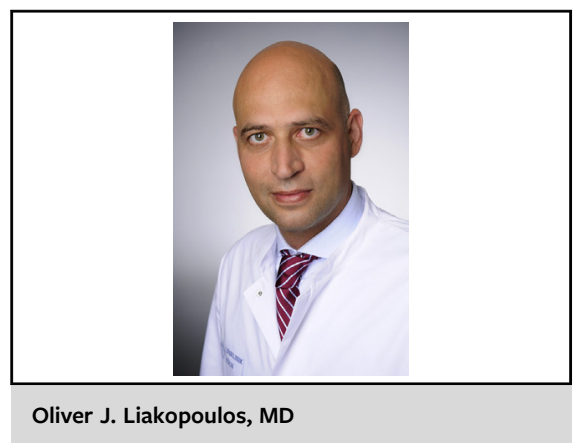

CENTRAL MESSAGE

Total autologous pericardial aortic and mitral valve reconstruction is presented as a feasible option for young patients with invasive aortomitral endocarditis.

outcomes after the hemi-Commando procedure tended to be superior to those after double-valve replacement with a 10 -year survival of $57 \%$, and fewer patients required reoperations $(45 \%)$ or had recurrent IE $(33 \%)$ at 8 years, thereby implicating a reduced risk in patients in whom repair of the native mitral valve is feasible.

In the present case report, Benedetto and colleagues ${ }^{4}$ go even further, by using exclusive autologous pericardial reconstruction of both left-sided valves and the aortomitral curtain in young patients with infective endocarditis. They combine the aortic valve neocuspidalization technique (AVNeo), also known as the Ozaki procedure, ${ }^{5}$ with transaortic mitral valve patch repair (hemi-Commando). Although technically challenging, this technique offers the advantage of a complete autologous repair and couples the excellent long-term durability and freedom from any reinfection rates reported by Ozaki and colleagues ${ }^{5}$ and Navia and colleagues, ${ }^{3}$ respectively. The latter might prove especially valuable for younger patients, in whom double valve replacement with mechanical prostheses is often considered the final option for many surgeons. The authors can certainly be congratulated for this innovative approach, but more patients with much longer follow-up are needed to confirm that the low rates of recurrent IE and structural aortic valve degeneration of glutaraldehyde-treated pericardial tissue as reported in series of Ozaki and colleagues, who included only patients with degenerative valve disease, are also reflected in patients with native IE. 


\section{References}

1. Pettersson GB, Hussain ST, Ramankutty RM, Lytle BW, Blackstone EH. Reconstruction of fibrous skeleton: technique, pitfalls and results. Multimed Man Cardiothorac Surg. 2014;2014:mmu004.

2. Igharably H, Hakim AH, Unai S, Hussain ST, Shrestha NK, Gordon S, et al. The incorporated aortomitral homograft for double-valve endocarditis: the "hemiCommando" procedure. Early and mid-term outcomes. Eur J Cardiothorac Surg. 2018;53:1055-61.

3. Navia JL, Elgharably H, Hakim AH, Witten JC, Haupt MJ, Germano E, et al Long-term outcomes of surgery for invasive valvular endocarditis involving the aortomitral fibrosa. Ann Thorac Surg. 2019;108:1314-23.

4. Benedetto U, Gergely S, Dmagli A, Sinha S. AVNeo (Ozaki) and transaortic mitra valve repair using autologous pericardium only for aortomitral endocarditis. $J$ Thorac Cardiovasc Surg Tech. 2020;3:101-3.

5. Ozaki S, Kawase I, Yamashita H, Uchida S, Takatoh M, Kiyohara N. Midterm outcomes after aortic valve neocuspidization with glutaraldehyde-treated autologous pericardium. J Thorac Cardiovasc Surg. 2018;155:2379-87. 